\title{
The Synthesis of $\mathrm{SiO}_{2} @ \mathrm{CdS}$ Nanocomposites Using Single-Molecule Precursors
}

\author{
Olinda C. Monteiro, Ana Catarina C. Esteves, and Tito Trindade* \\ Department of Chemistry, University of Aveiro, 3810-193 Aveiro, Portugal \\ Received October 12, 2001. Revised Manuscript Received April 10, 2002
}

\begin{abstract}
A chemical method for preparing cadmium sulfide nanocrystals over silica surfaces is reported. This is a one-step synthetic method involving the chemical degradation of al kyl dithiocarbamato complexes of cadmium in the presence of submicrometric $\mathrm{SiO}_{2}$ particles. The X-ray powder diffraction patterns of the $\mathrm{SiO}_{2} @ \mathrm{CdS}$ nanocomposites show diffraction peaks consistent with the presence of hexagonal CdS. Visible spectroscopy and scanning and transmission electron microscopy indicate that an inorganic composite formed by islands of $\mathrm{CdS}$ nanocrystals at the $\mathrm{SiO}_{2}$ surfaces. The $\mathrm{SiO}_{2} @ \mathrm{C} d \mathrm{~S}$ nanocomposites can, in turn, be capped with a protective layer of $\mathrm{SiO}_{2}$ using the Stöber method.
\end{abstract}

\section{Introduction}

Composite nanostructures have been the subject of intense research during the past few years. ${ }^{1-3} \mathrm{~A}$ number of reports on the synthesis of inorganic nanocomposites can be found in the literature, including $\mathrm{CdS} @ \mathrm{Cd}(\mathrm{OH})_{2}{ }^{4}$ $\mathrm{CdS} @ \mathrm{SiO}_{2}, \mathrm{SiO}_{2} @ \mathrm{ZnS}, 6 \mathrm{CdSe} @ \mathrm{CdS}, 7 \mathrm{CdS} @ \mathrm{PbS}^{8}$ CdS@ZnS, ${ }^{9}$ ZnS@CdSe, ${ }^{10}$ and CdSe@ZnS. ${ }^{11,12}$ Here, the terminology proposed ${ }^{1}$ for the designation of $\mathrm{C} 1 @ \mathrm{C} 2$ inorganic nanocomposites is followed: a C2 phase (shell) is covering a $\mathrm{C} 1$ phase (core). The synthesis of $\mathrm{C} 1 @ \mathrm{C} 2$ nanocomposites has been accomplished using distinct chemical methods, including epitaxial growth of semiconducting phases, ${ }^{13}$ nucleation and growth inside inverse micelles, ${ }^{10}$ reaction of molecular precursors, ${ }^{11}$ ultrasonic irradiation of colloidal solutions, ${ }^{6}$ and electroless deposition. ${ }^{14}$ Other chemical routes are yet to

* Correspondence should be addressed to Dr. Tito Trindade at Department of Chemistry, University of Aveiro, 3810-193 Aveiro, Portugal. E-mail: ttrindade@dq.ua.pt. Fax: +351 234370084 Phone: + 351234370726.

(1) Mulvaney, P.; Liz-Marzán, L. M.; Giersig, M.; Ung, T.J . Mater. Chem. 2000, 10, 1259.

(2) Ishida, H.; Campbell, S.; Blackwell, J . Chem. Mater. 2000, 12, 1260.

(3) Beecroft, L. L.; Ober, C. K. Chem. Mater. 1997, 9, 1302.

(4) Spanhel, L.; Haase, M.; Weller, H.; Henglein, A. J . Am. Chem. Soc. 1987, 109, 5649.

(5) Chang, S.; Liu, L.; Asher, S. A. J . Am. Chem. Soc. 1994, 116, 6739.

(6) Dhas, N. A.; Zaban, A.; Gedanken, A. Chem. Mater. 1999, 11, 806.

(7) Hao, E.; Sun, H.; Zhou, Z.; Liu, J .; Yang, B.; Shen, J. Chem. Mater. 1999, 11, 3096.

(8) Zhou, H. S.; Honma, I.; Komiyama, H.; Haus, J. W. J . Phys. Chem. 1993, 97, 895.

(9) Youn, H.; Baral, S.; Fendler, J . H. J . Phys. Chem. 1988, 92, 6320

(10) Kortan, A. R.; Hull, R.; Opila, R. L.; Bawendi, M. G.; Steigerwald, M. L.; Carroll, P. J .; Brus, L. E. J . Am. Chem. Soc. 1990, 112, 1327.

(11) Dabbousi, B. O.; Rodriguez-Viejo, J .; Mikulec, F. V.; Heine, J . R.; Mattoussi, H.; Ober, R.; J ensen, K. F.; Bawendi, M. G. J . Phys. Chem. B 1997, 101, 9463

(12) Talapin, D. V.; Rogach, A. L.; Kornowski, A.; Haase, M.; Weller, H. Nano Lett. 2001, 1, 207.

(13) Peng, X.; Schlamp, M. C.; Kadavanich, A. V.; Alivisatos, A. P. J . Am. Chem. Soc. 1997, 119, 7019.

(14) Kobayashi, Y.; Salgueiriño-Maceira, V.; Liz-Marzán, L. M. Chem. Mater. 2001, 13, 1630. be developed to allow for the preparation of a wider range of nanocomposites with controlled chemical compositions and well-defined morphological characteristics.

Single-mol ecule precursors have been investigated as an al ternative approach to the production of a range of semiconducting materials either as thin films ${ }^{15,16}$ or, more recently, as nanocrystalline materials. ${ }^{17,18}$ The single-source approach to the production of nanocomposite systems has not been investigated as thoroughly, although the thermalysis of mixed single-molecule precursors has been reported. ${ }^{19}$ It will be shown here that, under mild conditions, metal dithiocarbamato complexes can be used to prepare nanocomposite particles such as $\mathrm{SiO}_{2} @ \mathrm{CdS}$. This method clearly yields materials with properties distinct from those prepared by coprecipitation methods or by the thermalysis of molecular precursors in high-boiling-point solvents. For the $\mathrm{SiO}_{2} @ \mathrm{CdS}$ nanocomposites in particular, which could find use in photoelectrochemical cells or in luminescent devices, the use of a nanocrystalline semiconducting phase over $\mathrm{SiO}_{2}$ leads to a less expensive product and makes these materials technologically more interesting.

\section{Experimental Section}

All chemicals were supplied by Aldrich, except ethanol (Merck), and were used as received.

Preparation of $\mathbf{S i O}_{2}$ Particles. The silica particles were prepared using the Stöber method reported in the literature: $20.73 \mathrm{~g}$ of tetraethoxysilane (TEOS) was added to $5 \mathrm{~mL}$ of absolute ethanol containing $0.06 \mathrm{~g}$ of distilled water, and the mixture was allowed to stand for $30 \mathrm{~min}$. Subsequently, 2 $\mathrm{mL}$ of $\mathrm{NH}_{4} \mathrm{OH}$ solution (25\%) was added, and the solution was left to stand for $30 \mathrm{~min}$. The $\mathrm{SiO}_{2}$ colloid formed was filtered

(15) O'Brien, P.; Nomura, R. J . Mater. Chem. 1995, 5, 1761

(16) Bochmann, M. Chem. Vap. Deposition 1996, 2, 85

(17) Trindade, T.; O'Brien, P.; Zhang, X. Chem. Mater. 1997, 9, 523.

(18) Monteiro, O. C.; Nogueira, H. I. S.; Trindade, T.; Motevalli, M. Chem. Mater. 2001, 13, 2103.

(19) Ravaprasadu, N.; Malik, M. A.; O'Brien, P.; Wakefield, G. Chem. Commun. 1999, 1573.

(20) Stöber, W.; Fink, A.; Bohn, E. J . Colloid Interface Sci. 1968, 26,62 . 
and washed thoroughly with water and ethanol. The $\mathrm{SiO}_{2}$ particles were used as prepared (untreated $\mathrm{SiO}_{2}$ ) or after thermal treatment at $700{ }^{\circ} \mathrm{C}$ for $4 \mathrm{~h}$ (treated $\mathrm{SiO}_{2}$ ). This thermal treatment increased the degree of dehydroxylation of the silica surface.

Synthesis of Dialkyldithiocarbamato Cadmium Complexes $\mathbf{C d}\left[\mathbf{S}_{\mathbf{2}} \mathbf{C N R R ^ { \prime }}\right]_{2}$. The precursors for $\mathrm{CdS}$ were prepared as reported previously. ${ }^{17}$ (CAUTION: Because of cadmium toxicity, wear protective gloves when manipulating $\mathrm{Cd}$ containing compounds.) Typically, $20 \mathrm{mmol}$ of the secondary amine (diethylamine or n-hexylmethylamine) and $1.1 \mathrm{~mL}$ (13.5 $\mathrm{mmol}$ ) of $\mathrm{CS}_{2}$ were added to a dispersion containing $1.42 \mathrm{~g}$ (10 $\mathrm{mmol})$ of $\mathrm{Cd}(\mathrm{OH})_{2}$ in ethanol $(50 \mathrm{~mL})$. The mixture was stirred for $2 \mathrm{~h}$, and the solid obtained was isolated by filtration and washed with ethanol. The cadmium complexes were identified by IR and ${ }^{1} \mathrm{H}$ NMR spectroscopies.

Preparation of $\mathbf{S i O}_{\mathbf{2}} @ \mathbf{C d S}$ Nanocomposites. The nanocomposite particles were prepared by adding ethylenediamine $(2.5 \mathrm{~mL})$ dropwise to an acetone sol ution $(47.5 \mathrm{~mL})$ containing $0.25 \mathrm{mmol}$ of the cadmium alkyldithiocarbamate and $0.25 \mathrm{~g}$ of $\mathrm{SiO}_{2}$ particles. The suspension was then refluxed with stirring for a certain period of time under a $\mathrm{N}_{2}$ stream inside a well-ventilated fume hood. The bright yellow solid obtained was collected by centrifugation and washed thoroughly with acetone. The powder obtained was dried at room temperature in a desiccator over silica gel.

Instrumentation. Spectroscopic Methods. Diffuse reflectance spectra of the $\mathrm{SiO}_{2} @ \mathrm{CdS}$ powders, obtained as described above, were recorded on a J asco V-560 UV/vis spectrophotometer using $\mathrm{MgO}$ as the reference. NMR spectra were recorded on a Bruker AMX 300 spectrometer using acetone-d ${ }^{6}$ as the solvent. I nfrared spectra were recorded on a Matson 700 FTIR spectrometer using dry Csl disks. Photoluminescence (PL) measurements obtained at room temperature (RT) were carried out with a 325-nm CW He-Cd laser. The luminescence was dispersed by a Spex 1704 monochromator (1 m, 1200/mm) and detected with a Hamamatsu R928 photomultiplier. X-ray photoelectron spectra (XPS) were measured using an LAS ESCALAB 200A instrument, using the AI K $\alpha$ line as the X-ray source on powders dispersed on carbon tape.

Powder Diffraction and Electron Microscopy Techniques. X-ray powder diffraction (XRD) was performed using a Philips instrument operating with $\mathrm{Cu} \mathrm{K} \alpha$ radiation $(\lambda=1.54178 \AA$ ) at $40 \mathrm{kV}$ and $50 \mathrm{~mA}$.

Transmission electron microscopy (TEM) was carried out on a Hitachi $\mathrm{H}-9000$ microscope operating at $300 \mathrm{kV}$. The samples were prepared as follows: an aliquot containing the nanocomposite dispersed in acetone was placed on a copper grid coated with an amorphous carbon film, and then the solvent was evaporated.

Scanning electron microscopy (SEM) images and energydispersive X-ray spectroscopy (EDAX) were performed using a FEG-SEM Hitachi S4100 microscope operating at $25 \mathrm{kV}$. The samples were prepared by depositing an aliquot of the suspension of the nanocomposite in acetone onto aluminum pieces and then coating them with Au/Pd or evaporated carbon.

\section{Results and Discussion}

Cadmium dithiocarbamato complexes have been investigated as suitable single sources for the preparation of CdS nanocrystals. ${ }^{17} \mathrm{~A}$ possible approach described in the literature involves thermal decomposition of the precursor in a high-boiling-point coordinating solvent such as tri-n-octyl phosphine oxide (TOPO). ${ }^{17}$ Using this method, high-quality nanocrystals showing a passivated surface with TOPO molecules have been obtained. To prepare $\mathrm{SiO}_{2} @ \mathrm{CdS}$ nanocomposite particles, thermal decomposition of a single-molecule precursor in the presence of $\mathrm{SiO}_{2}$ particles and TOPO was first attempted. However, our preliminary experiments showed that a mixture of segregated $\mathrm{SiO}_{2}$ and $\mathrm{CdS}$ phases was

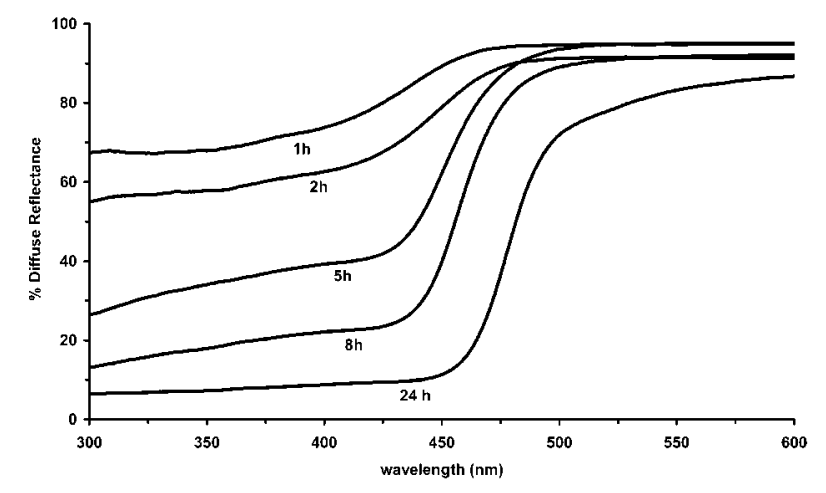

Figure 1. Diffuse reflectance spectra of $\mathrm{SiO}_{2} @ \mathrm{CdS}$ nanocomposites collected at different reaction times.

obtained, along with the desired product $\mathrm{SiO}_{2} @ \mathrm{CdS} .{ }^{21}$ The preparation of $\mathrm{SiO}_{2} @ \mathrm{CdS}$ particles using cadmium dithiocarbamates was then investigated by an alternative method in which lower temperatures were used. In this method, well-defined synthetic $\mathrm{SiO}_{2}$ particles act as substrates favoring the formation of morphologically uniform particles of the nanocomposite. This mildtemperature deposition method involves the chemical degradation of the precursor in the presence of ethylenediamine, possibly mediated by the formation of a cadmium coordination compound containing the dithiocarbamato and ethylenediamine ligands. ${ }^{22}$

In the work reported here, the compounds $\mathrm{Cd}\left[\mathrm{S}_{2} \mathrm{CN}\right.$ $\left.\left(\mathrm{CH}_{3}\right)\left(\mathrm{C}_{6} \mathrm{H}_{13}\right)\right]_{2}$ and $\mathrm{Cd}\left[\mathrm{S}_{2} \mathrm{CN}\left(\mathrm{C}_{2} \mathrm{H}_{5}\right)_{2}\right]_{2}$ were used as single sources for the deposition of $\mathrm{CdS}$ onto $\mathrm{SiO}_{2}$. The two precursors yielded nanocomposites with similar optical and morphological properties. The results presented refer to the use of $\mathrm{Cd}\left[\mathrm{S}_{2} \mathrm{CN}\left(\mathrm{CH}_{3}\right)\left(\mathrm{C}_{6} \mathrm{H}_{13}\right)\right]_{2}$ as a single-molecule precursor. It was found that the time and temperature of the reaction had a strong influence on the optical and morphological properties of the final $\mathrm{SiO}_{2} @ \mathrm{CdS}$ particles. This is clearly shown in Figure 1, which presents the diffuse reflectance spectra of the powders collected at different reaction times. For the short reaction times, the optical band gap of the CdS phase is blue-shifted from the typical $\mathrm{E}_{\mathrm{g}}$ at $2.5 \mathrm{eV}(512$ $\mathrm{nm}$ ) of the semiconductor. A result consistent with the presence of quantum-sized CdS at the surface of the $\mathrm{SiO}_{2}$ particles. As the reaction time increases, the band edge (Figure 1 ) approaches the typical $E_{g}$ value of macrocrystalline CdS. This is in agreement with a process in which the CdS nanoparticles located at the $\mathrm{SiO}_{2}$ surfaces grow into crystallites of larger dimensi ons as the reaction proceeds. For samples collected at various times ( $F$ igure 1 ), the percentage of reflectance observed within the 300-500 $\mathrm{nm}$ region decreases for longer reaction times, as expected for an increasing amount of $\mathrm{CdS}$ covering the $\mathrm{SiO}_{2}$ surfaces.

Figure 2 shows the XRD patterns for a typical $\mathrm{SiO}_{2} @ \mathrm{CdS}$ nanocomposite sample. The XRD performed on the $\mathrm{SiO}_{2} @ \mathrm{CdS}$ nanocomposites showed broad features at $2 \theta$ values of $27^{\circ}, 35^{\circ}, 44^{\circ}, 48^{\circ}$, and $52^{\circ}$, consistent with the presence of hexagonal CdS as the predominant crystalline phase. ${ }^{23}$ Because of the small

(21) Monteiro, O. C.; Esteves, A. C. C.; Trindade, T. Presented as the 1st COST D19 Workshop on Nanomaterials, Coimbra, Portugal, Sep 21-22, 2001.

(22) Glinskaya, L. A.; Zemskova, S. M.; Klevtsova, R. F .; Larionov, S. V.; Gromilov, S. A. Polyhedron 1992, 11, 2951. 


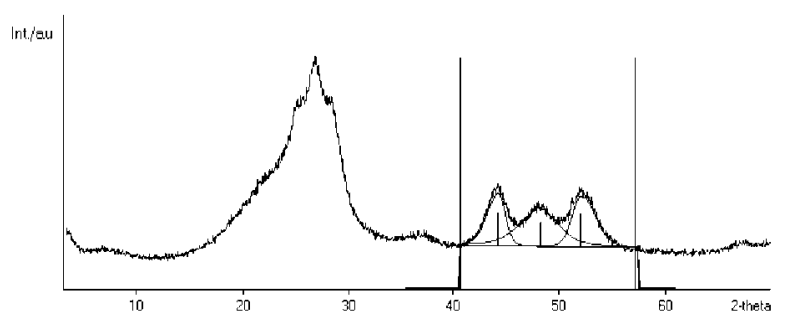

Figure 2. Typical XRD patterns of $\mathrm{S} \mathrm{SiO}_{2} @ \mathrm{CdS}$ nanocomposite.

particle size, band broadening is observed, precluding a definite conclusion regarding the presence of vestigial cubic CdS. The $\mathrm{SiO}_{2}$ particles also contribute to the peak broadness observed at lower diffraction angles. The crystalline phase present in the $\mathrm{SiO}_{2} @ \mathrm{CdS}$ samples was confirmed by selected area transmission electron diffraction performed on the nanocomposites. The $\mathrm{SiO}_{2} @ \mathrm{CdS}$ el ectron diffraction patterns, typical of hexagonal CdS, appeared as diffuse rings, as expected for a sample consisting of particles of nanometric dimensions. EDAX measurements performed at the surface of the particles showed peaks for $\mathrm{Cd}$ and $\mathrm{S}$, as well as $\mathrm{Si}$ from the substrate.

In a control experiment, it was found that the nanocomposites showed distinct optical properties and different diffraction patterns from the powders obtained by the direct precipitation of $\mathrm{CdS}$ over $\mathrm{SiO}_{2}$ using $\mathrm{Cd}^{2+}$ and $\mathrm{S}^{2-}$ solutions. This distinction was immediately obvious by visual inspection of the final powders, in which the latter material showed a pale orange color, instead of the bright yellow appearance of the $\mathrm{SiO}_{2} @ \mathrm{C} d \mathrm{~S}$ nanocomposites prepared by the single-source method. Also, the X-ray diffraction patterns of the materials obtained from the direct precipitation of $\mathrm{CdS}$ over $\mathrm{SiO}_{2}$ particles is consistent with the presence of a mixture of $\mathrm{CdSiO}_{4}$ and $\mathrm{CdS}$ phases. Asher et al. reported ${ }^{5}$ the preparation of cubic $\mathrm{CdS} / \mathrm{SiO}_{2}$ nanocomposites of diverse morphologies using microemulsions as templates. It is interesting to note that the method reported here yields $\mathrm{SiO}_{2}$ nanocomposites containing hexagonal $\mathrm{CdS}$, thus allowing for the preparation of nanocomposites containing a CdS polymorph distinct from that present in the materials described by Asher. ${ }^{5}$ The domain size for nanocrystalline $\mathrm{CdS}$ obtained here was estimated by applying the Scherrer formula to the $44^{\circ}$ and $52^{\circ} 2 \theta$ reflections in the XRD patterns for samples collected at reaction times of 24,48 , and 60 h (i.e., 1, 2, and 5 days). The particle dimensions estimated by this method range from 37 to $42 \AA$ in diameter. This result agrees with the presence of nanocrystalline CdS, for which quantum size effects are expected.4,17 In this case, the size domain for the CdS particles should be carefully considered, al though it is clearly within the nanometric range. In fact, the XRD particle size analysis is based on the crystalline domains; hence, CdS particles with an incomplete band structure do not contribute significantly to the X-ray diffraction pattern. A more detailed morphological analysis was performed on the $\mathrm{SiO}_{2} @ \mathrm{CdS}$ samples using SEM and TEM techniques.

Figure 3 a shows a SEM image of a thermally treated $\mathrm{SiO}_{2}$ particle. The SEM images of $\mathrm{SiO}_{2} @ \mathrm{CdS}$ nanocomCDD. (a)

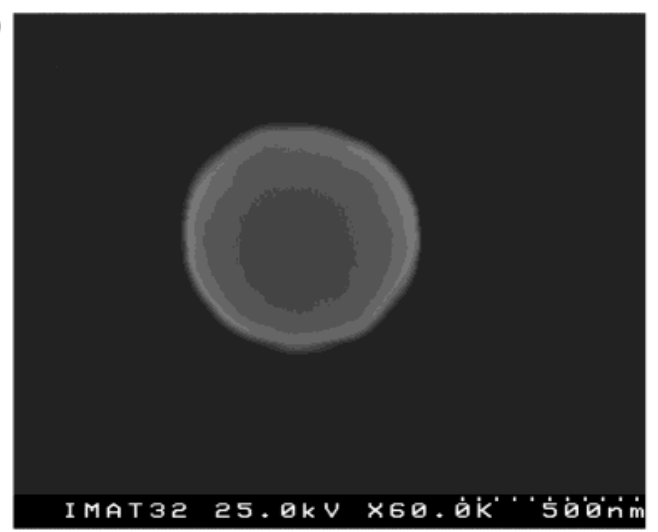

(b)

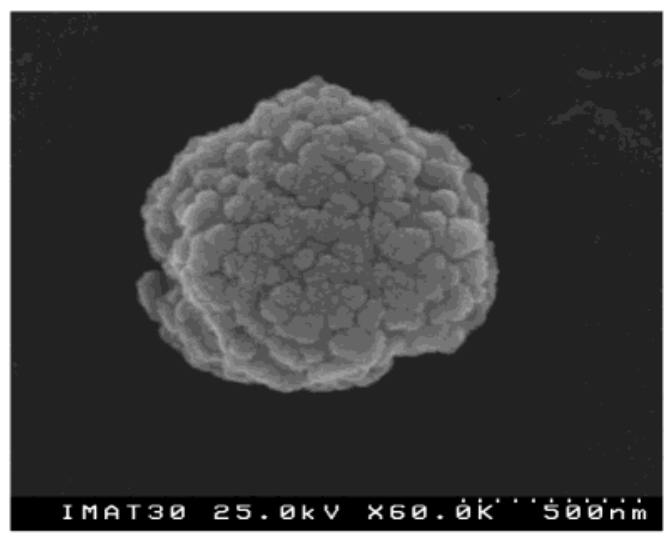

(c)

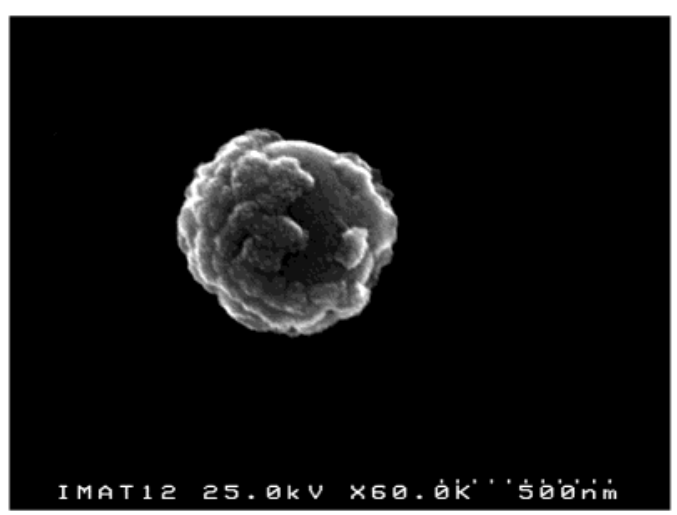

Figure 3. SEM images of $\mathrm{SiO}_{2} @ \mathrm{CdS}$ nanocomposites collected at different reaction times: (a) $t=0 \mathrm{~h}$, (b) $\mathrm{t}=8 \mathrm{~h}$ (using thermally treated $\mathrm{SiO}_{2}$ ), (c) $\mathrm{t}=48 \mathrm{~h}$ (using untreated $\mathrm{SiO}_{2}$ ).

posites prepared at different reaction times, using treated $\mathrm{SiO}_{2}$ or untreated $\mathrm{SiO}_{2}$, are shown in Figure $3 \mathrm{~b}, \mathrm{c}$, respectively. The nanocomposite particles prepared for $8 \mathrm{~h}$ using thermally treated $\mathrm{SiO}_{2}$ particles are completely coated with CdS. The SEM images (Figure $3 b, c)$ suggest that the outer layer is formed of $\mathrm{CdS}$ islands, ca. $50 \mathrm{~nm}$ in size, at the surface of the $\mathrm{SiO}_{2}$ particles. This is a size domain for which quantum size effects would not be expected (for nanocrystalline CdS) because it is considerably larger than the Bohr radius of the bulk exciton for the semiconductor. However, it is clear from Figure 1 that the $\mathrm{SiO}_{2} @ \mathrm{CdS}$ nanocomposites show quantum size effects in their optical spectra; also, the domain sizes estimated from the Scherrer formula are within the quantum size regime for CdS. Moreover, preliminary photoluminescence studies performed for the $\mathrm{SiO}_{2} @ \mathrm{C} d \mathrm{~S}$ nanocomposites showed a 


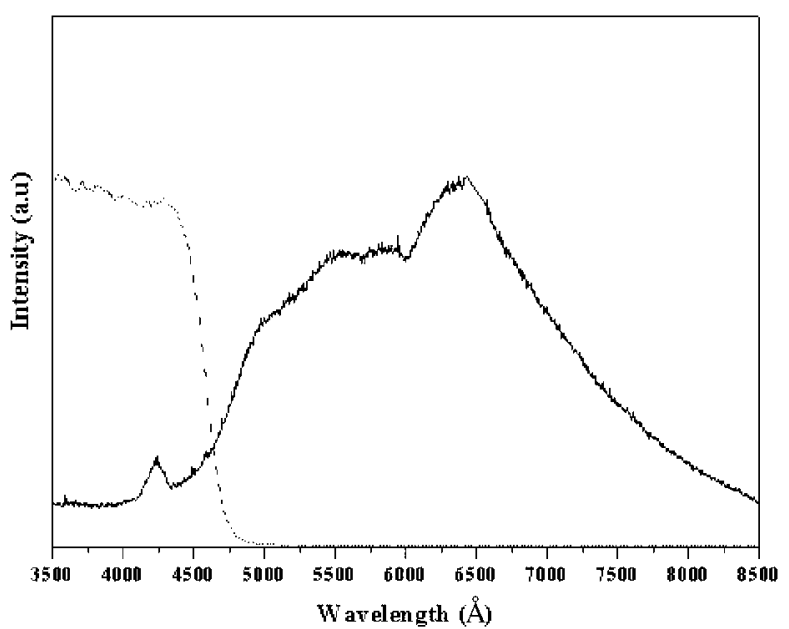

Figure 4. Visible diffuse reflectance (dashed line) and photoluminescence (solid line) spectra of $\mathrm{SiO}_{2} @ \mathrm{CdS}$ nanocomposites.

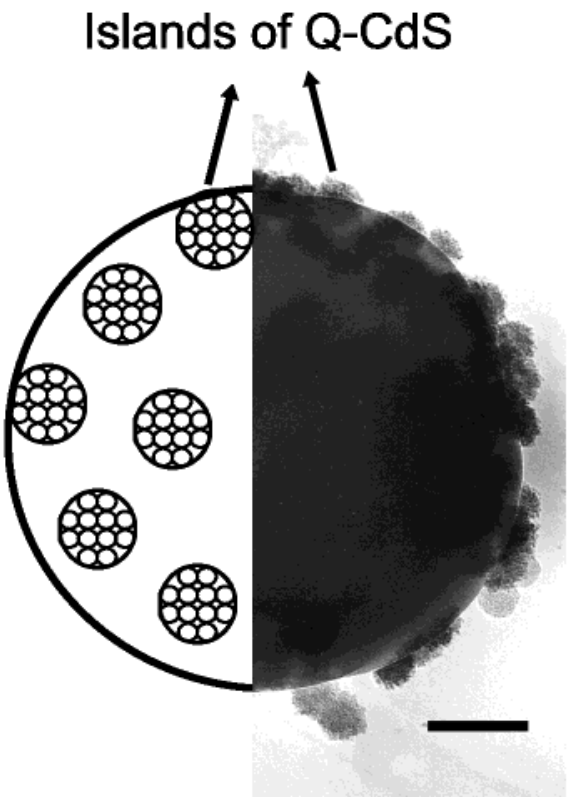

Figure 5. TEM image (bar $=140 \mathrm{~nm}$ ) and diagrammatic picture of a $\mathrm{SiO}_{2} @ \mathrm{CdS}$ nanocomposite particle showing nanosized $\mathrm{CdS}$ forming islands at the $\mathrm{SiO}_{2}$ surface.

structured band emission distinct from the bulk CdS emission that is slightly red-shifted from the optical band gap of the same sample (Figure 4 ). This result is consistent with the presence of CdS nanocrystals. 24,25 The experimental evidence for the presence of $\mathrm{CdS}$ nanocrystals smaller than the islands indicates that the CdS nanocrystals might cluster and form the islands observed by SE M. The morphological nature of the CdS layer was further investigated by a close inspection of the $\mathrm{CdS}$ formed at the $\mathrm{SiO}_{2}$ surfaces using TEM. Figure 5 shows the TEM image of a $\mathrm{SiO}_{2} @ \mathrm{CdS}$ nanocomposite particle formed by clustered CdS nanocrystals at the $\mathrm{SiO}_{2}$ surface. This result is in agreement with the relatively broad emission band observed in Figure 4. ${ }^{24,25}$

Although detailed mechanistic studies are beyond the scope of this work, the $\mathrm{SiO}_{2} @ \mathrm{CdS}$ nanocomposites might

(24) Chestnoy, N.; Harris, T. D.; Hull, R.; Brus, L. E. J . Phys. Chem. 1986, 90, 3393.

(25) Liu, B.; Xu, G. Q.; Gan, L. M.; Chew, C. H. J . Appl. Phys. 2001 89, 1059. result from CdS nanocrystals acting as nuclei for further growth of the $\mathrm{CdS}$ phase at the $\mathrm{SiO}_{2}$ surface. An island growth mechanism could explain the formation of the CdS phase. In agreement with this process, the number density of $\mathrm{CdS}$ islands at the $\mathrm{SiO}_{2}$ surfaces increased with reaction time, i.e., as the molecular precursor is consumed. For longer reaction times, the $\mathrm{SiO}_{2}$ particles became completely coated with CdS (Figure $3 \mathrm{~b}$ ). Coating $\mathrm{SiO}_{2}$ substrates using metals or semiconductors has been reported to involve migration and coalescence of nanoparticles following an island growth process. ${ }^{26}$ This mechanism seems to apply not only to large substrates but also to submicron-sized $\mathrm{SiO}_{2}$ particles, as suggested here and recently in the sonochemical preparation of $\mathrm{SiO}_{2} @ Z n S$ nanocomposites. ${ }^{6}$

It is not clear whether the nanocrystals start to nucleate at the surface of the $\mathrm{SiO}_{2}$ microparticles or are formed in solution and then migrate to the $\mathrm{SiO}_{2}$ surface. The first event, corresponding to a heterogeneous nucleation process, is well-known to be more favorable than a homogeneous nucl eation process (corresponding to the latter event). However, this distinction applied to the system under study is not straightforward, because other processes can be important. For example, small CdS nuclei could be formed at the $\mathrm{SiO}_{2}$ surface and then migrate to the solution, where an Ostwald mechanism would generate larger particles. The fact that encapsulation of the thermally treated $\mathrm{SiO}_{2}$ particles (at $700{ }^{\circ} \mathrm{C}$ during $4 \mathrm{~h}$ ) was more effective than that of the untreated counterparts, as shown in Figure $3 \mathrm{~b}$ and $\mathrm{c}$, led us to conclude that a surface-nucleated process is predominant for the formation of the CdS nanocrystals.

It was found that the $\mathrm{SiO}_{2} @ \mathrm{CdS}$ particles can be covered by a $\mathrm{SiO}_{2}$ shell simply by using the Stöber method employed to obtain the $\mathrm{SiO}_{2}$ spheres. The coating process of $\mathrm{SiO}_{2} @ \mathrm{CdS}$ was monitored using XPS measurements (Figure 6). As expected, the $\mathrm{Cd}$ and $\mathrm{S}$ peaks assigned to the CdS phase are present in the $\mathrm{SiO}_{2} @ \mathrm{CdS}$ nanocomposites (Figure 6b) as compared to the naked $\mathrm{SiO}_{2}$ particles (Figure 6a). The XPS measurements performed for $\mathrm{SiO}_{2} @ \mathrm{CdS}$ particles covered with a $\mathrm{SiO}_{2}$ layer showed $\mathrm{Cd}$ and $\mathrm{S}$ peaks that were considerably less intense when compared with the Si peak (Figure $6 \mathrm{C}$ ). This $\mathrm{SiO}_{2}$ coating was confirmed by TEM measurements, although aggregation of the particles also occurred to some extent by applying directly the Stöber method to the "as-prepared" $\mathrm{SiO}_{2} @ \mathrm{CdS}$ nanocomposites. The previous chemical surface treatment of the $\mathrm{SiO}_{2} @ \mathrm{CdS}$ nanocomposites might improve their final morphological properties, following similar procedures described in the literature. ${ }^{27}$ Moreover, surface treatment using the appropriate capping molecules would make these nanocomposites compatible with organic matrices. The silica encapsulation of semiconductors and metal nanocrystals has recently been reviewed. ${ }^{1}$ The importance of silica encapsulation of inorganic particles has been long recognized. F or example, in the pigments industry, some inorganic pigments require a stabilization step, consisting of coating of the pigment using a robust chemical material such as $\mathrm{SiO}_{2}$ or

(26) Shirakawa, H.; Komiyama, H. J . Nanopart. Res. 1999, 1, 17

(27) Correa-Duarte, M. A.; Giersig, M.; Liz-Marzán, L. M. Chem. Phys. Lett. 1998, 286, 497. 
(a)

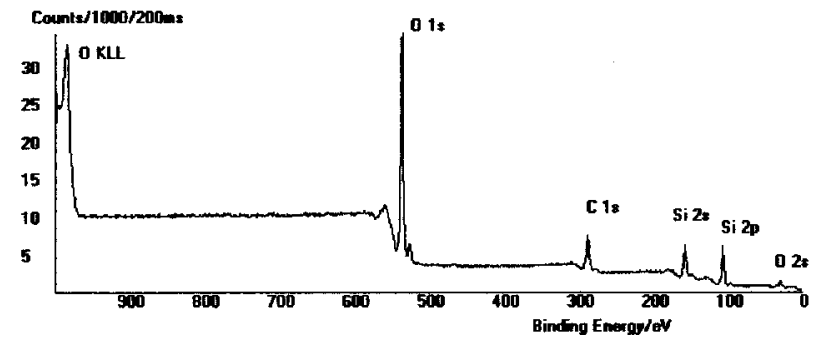

(b)

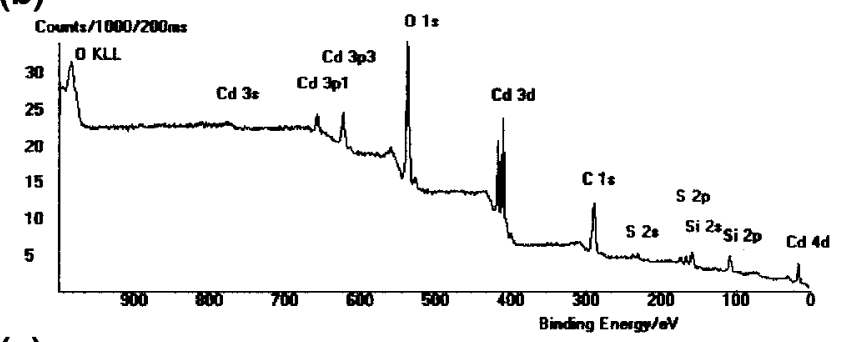

(c)

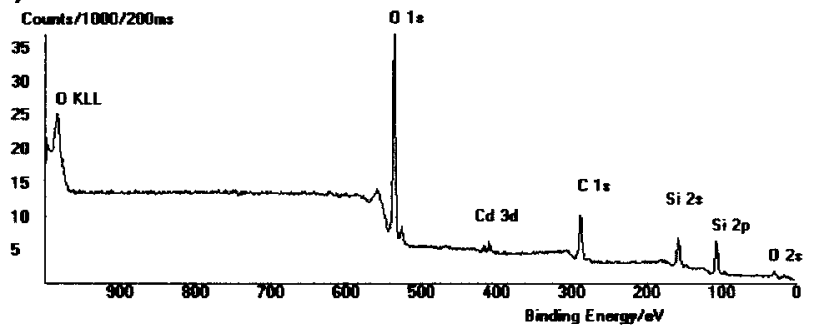

Figure 6. XPS spectra: (a) $\mathrm{SiO}_{2}$, (b) $\mathrm{SiO}_{2} @ \mathrm{CdS}$, and (c) $\mathrm{SiO}_{2-}$ coated $\mathrm{SiO}_{2} @ \mathrm{CdS}$.

$\mathrm{Al}_{2} \mathrm{O}_{3} .{ }^{28}$ There are obvious reasons for producing coated pigment particles, such as chemical protection of the core or improvement of its thermal stability. In the particular case of the $\mathrm{SiO}_{2} @ \mathrm{CdS}$ materials reported here, there are additional advantages. In fact, the disordered surface of the semiconductor is passivated

(28) Industrial Inorganic Pigments, 2nd ed.; Buxbaum, G., Ed.; Wiley-VCH: New York, 1998. by amorphous phase-filling surface defects, hence promoting the optical properties of the material ${ }^{29}$ and enhancing its photochemical stability. ${ }^{27}$ Also, the toxic CdS phase is not available for direct contact with biological systems.

\section{Conclusions}

In summary, $\mathrm{SiO}_{2} @ \mathrm{C} d \mathrm{~S}$ nanocomposites can be prepared using a single-source method under mild conditions. This method establishes an alternative route for the preparation of nanocomposites based on a semiconducting phase on submi crometric $\mathrm{SiO}_{2}$ particles. Moreover, it was observed that the nanocomposites obtained by this method show properties distinct from those of the anal ogues prepared by traditional synthetic routes such as coprecipitation. Mechanistic studies using these types of systems would be of great interest from both technological and purely academic perspectives. In fact, the mechanism involved would probably make use of our actual knowledge of the reactivity of soluble molecular species at the surfaces of a heterogeneous system to form a crystalline solid phase. The mild temperatures employed in the synthetic method reported here are compatible with the preparation of inorganic/organic hybrid materials, for example, by blending the capped $\mathrm{SiO}_{2} @ \mathrm{CdS}$ particles with polymers.

Acknowledgment. O. Monteiro thanks FCT for a PhD grant; A. Esteves thanks the University of Aveiro for a research grant. We thank Ms. Márcia Neves (SEM results), Dr. Rosário Soares (XRD results), Dr. Teresa Monteiro (PL measurements), and Dr. Carlos Sá (XPS measurements) for assistance. This work was financed by Fundação para a Ciência e Tecnologia (Project POCTI/35458/CTM/2000 co-financed by FEDER).

CM011257E

(29) Bruchez, M., J r.; Moronne, M.; Gin, P.; Weiss, S.; Alivisatos, A. P. Science 1998, 281, 2013. 